\title{
Web Application and GPS Integration in Motor Vehicle Accident Detection - A Case of Nairobi, Kenya
}

\author{
Peter N. Njuguna \\ School of Computing and \\ Informatics, \\ University of Nairobi, Kenya
}

\author{
Andrew M. Kahonge \\ School of Computing and \\ Informatics, \\ University of Nairobi, Kenya
}

\author{
Evans K. Miriti \\ School of Computing and \\ Informatics, \\ University of Nairobi, Kenya
}

\begin{abstract}
When accidents occur, help to the victims is delayed mostly due to lack of prompt detection and reporting. Further, an easily accessible electronic motor vehicle accident database does not exist in Kenya. In an attempt to tackle these problems, a technique for automatically detecting and reporting accidents to relevant authorities is presented. In this technique, several technologies have been integrated and they include; impact sensors, Global Positioning System (GPS), Geographical Information System (GIS), Global System for Mobile Communication (GSM), Electronic Database System, the internet and web programming. In evaluating the technique, over fifty impacts were generated in experiments using a software and hardware prototype that was developed as part of this work. It is found that 98 percent of impacts were successfully transmitted and updated on the database as accidents, within an impressive average time of fifteen seconds. Additionally, authorized web clients could access this information immediately.
\end{abstract}

\section{General Terms}

Web Application, GIS.

\section{Keywords}

Web Application, Geographical Positioning System (GPS), Geographical Information System (GIS), Impact Sensors, Global System for Mobile Communication (GSM).

\section{INTRODUCTION}

Kenya had 3,760 traffic deaths, the highest in East Africa region. Approximately 1.3 million people die each year on the world's roads, and between 20 and 50 million sustain non fatal injuries [1]. The common types of motor vehicle accidents are; vehicle collision - where two or more motor vehicles are involved, rollover or overturning, collision against stationary objects - for example collision against rocks, solid concrete, buildings and trees and knocking against pedestrians and animals. Accidents are caused by many factors including the design and condition of the road, over speeding, loss of control by the driver, obstruction and vehicle malfunction.

Effects of motor vehicle accidents are disastrous and include injuries, deaths, and loss of property [8]. These impacts heavily on the economy and emotions of the nation and families involved.

Delays in detecting and reporting accidents make worse the above consequences of motor vehicle accidents [3]. Related closely with this problem, is the unavailability of reliable source of comprehensive and all inclusive accident data in Kenya [1]. Therefore there is need to develop a solution for near instant motor vehicle accident detection and reporting, that will also keep electronic records of accidents in a web based database for easy access [10].

\section{PREVIOUS EFFORTS IN MOTOR VEHICLE ACCIDENT DETECTION AND REPORTING}

There are many road accidents that are not reported to the police [2]. Injuries following road traffic accidents (RTA) are common in Nairobi. The response to injury is slow and haphazard [3].

In Kenya and more specifically in the city of Nairobi, motor vehicle accidents are detected and reported to the police or hospitals by way of telephone calls or physical visits. Accidents are detected by chance and in most cases after a considerable amount of time, when some victim's lives cannot be saved, injuries are extensive and property stolen or damaged.

The deficiency of a systematic way of reporting road carnage is a serious fault resulting to avoidable deaths at the accidents scene [3]. In a study aimed at developing a road accident computerized system in Thailand [4] observed there are problems of accident under-reporting and accident reported matching. This is due to the lack of asynchronous and efficient method of reporting and recording accidents

\section{METHODOLOGY}

The goal was to come up with a prototype of a solution for near instant detection and reporting of a motor vehicle accident. The block diagram below represents the conceptual model of the solution. The solution is an innovation using existing technologies and it is in three modules, namely the accident detection, the vehicle tracking and the accident surveillance modules.

\subsection{The Accident Detection Module}

It consists of impact sensors, Electronic Control Unit (ECU) for accident detection logic processing and signal conditioning electronics. The impact sensor senses all vehicle impacts and sends the appropriate signal to the processor (ECU). The electronic control unit (ECU) continuously checks the status of the sensors and determine impact signal that meets a pre-set threshold. It also sends the accident occurrence signal to the communication transceiver component of the GPS device. This arrangement is similar to the event detection module developed by [9]. 


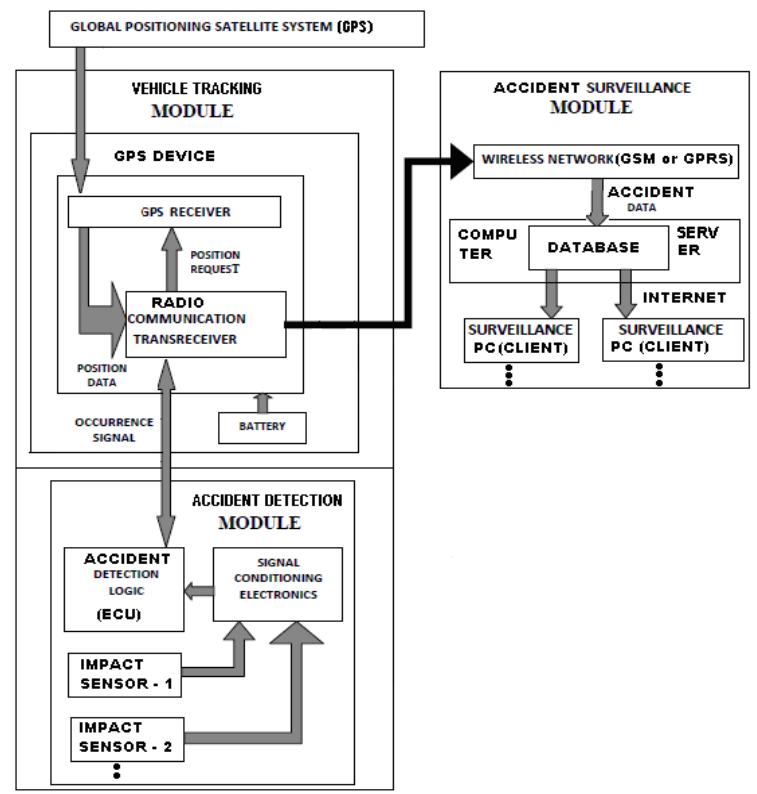

Fig 1. The Conceptual model

The impact sensors used in this system are based on accelerometers [6]. A motor vehicle crash impact is sensed as when the rate of deceleration exceeds a certain pre-determined threshold. In their quest to develop an intelligent safety system (ISS) for vehicles applications, [5] noted that, the change in vehicle velocity, $\Delta v(t)$ is an essential parameter for crash detection and they used it in the development of their crash detection algorithm. They further averred that $\Delta v(t)$ is obtained by integrating the acceleration signal as shown below.

$$
\Delta v(t)=\int a(t) \cdot d t=A \omega \int \cos (\omega t+\delta)
$$

A suitable vehicle velocity threshold, $V_{\text {threshold }}$, is required to facilitate decision making as to whether or not a crash has effectively occurred. To detect a crash, they used the following algorithmic steps;

- $\quad$ If $\Delta v(t) \geq V_{\text {threshold }}$, then output $=1$; DECISION: Effective crash is detected

- $\quad$ If $\Delta v(t)<V_{\text {threshold }}$, then output $=0$; DECISION: Effective crash is not detected

\subsection{Vehicle Tracking Module}

It is comprised of a GPS unit composed of GPS receiver and the radio communication transceiver. The GPS unit receives signals from satellites in global positioning satellite system [7]. These signals are processed to identify the geographic location of the GPS receiver according to the well known GPS technology. The GPS device is powered by the battery or some power adapter. The GPS device in use operates in such a manner so as to conserve the consumption of the power. The GPS device has a communication transceiver, which is a cellular-based transceiver used to receive accident occurrence signal and transmit signals to the wireless GSM network for interfacing with server database and subsequently enabling the display of the accident detected.

\subsection{Accident Surveillance Module}

This is a prototype based on a computer consisting of wireless network, database, the Internet and web clients. The wireless network used utilizes GSM and GPRS technology and is facilitated by Safaricom mobile telephone provider. The database is hosted on a computer, for access by all accident detection GPS devices. To access and display accident data as stored on the database, clients use the internet technology. Authorized clients receive accident occurrence details on their workstations showing the details of the vehicle and the location. The location is also displayed on a GIS digital map similar to the one shown on figure 2 below. Further email and SMS messages for new accident occurrences received at the database are sent to established contacts including the police, and hospitals.

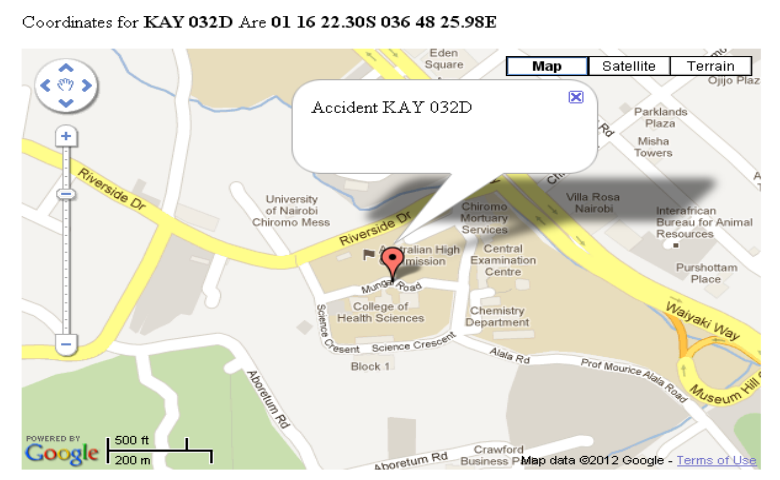

Fig 2. The Sample accident site display on GIS map

\subsection{Web Interface}

The host computer maintains all information received from all vehicle units installed in different vehicles into a central database available on web platform as Gupta, M. at el established in their study [10]. The computer receives information from accident GPS devices through a GSM phone attached to it. This information is saved into a database and has an interface capable of displaying the information on the database and also responding to HTTP requests from client stations. To generate an answer to requests, a software module will read data from the database. This software is programmed in C\# (pronounced as C Sharp) and it is interpreted by web browsers. This solution can be launched on the internet by hosting it on a server based at an ISP (internet service provider). It is accessible from the internet to users through a web interface. Accident occurrences on the database are displayed on web client station and can be displayed on GIS based digital maps using appropriate application programming interface (API) [12]. In a practical scenario motor vehicles will be installed with accident detection units. Therefore the database must be able to manage and distinguish information sent by all vehicles units. For this purpose information must be available to server about all vehicles that are installed with accident detection units. Whenever accident detection unit is installed, information about the vehicle is stored in the database. The front end software has a module for this maintenance through web interface. Access to the database is restricted to authorized users only and therefore information about all special users of the system must be maintained.

\section{GENERAL PROCEDURE}

The general procedure followed by the system is as depicted in figure 3. The impact sensors detect an impact and transmit electronic signal to an Electronic Control Unit (ECU) which has the logic processor to determine the level of the impact. When the impact magnitude exceeds a pre-set threshold, the ECU re-transmits the signal to a Geographical Positioning System (GPS) device that is interfaced to it. As soon as the GPS device receives the signal, the GSM component transmits a GPS message to a pre-configured wireless contact. 


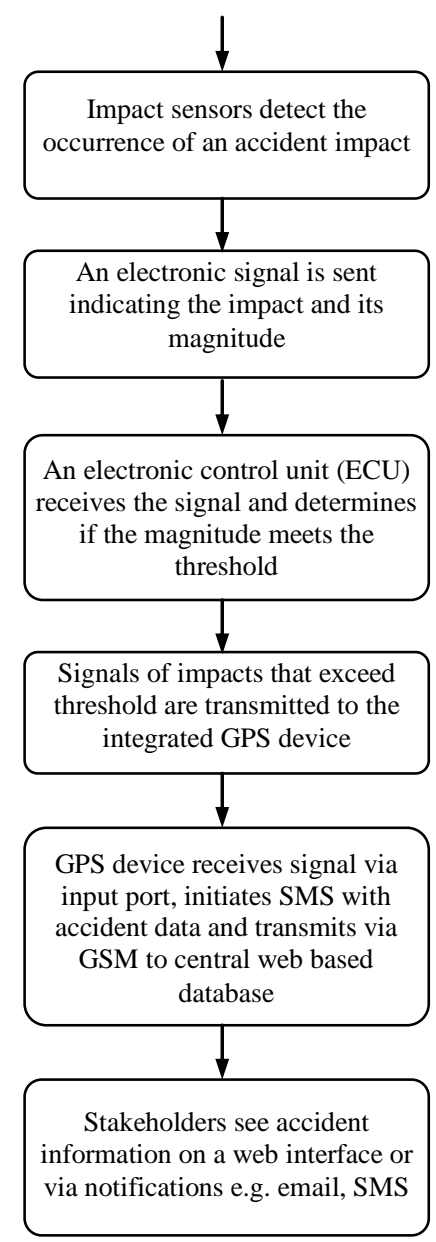

Fig 3. Flowchart of the general procedure

Similar to previous studies conducted [13] this message contains the spatial data of the accident location, the GPS device unit ID, the date and time of the impact, the speed of the vehicle at the time of the crash, and a keyword 'SOS alert'. This message is received at a GSM modem SIM card where it is read into a web based accident database. Details of vehicles fitted with the detection system are pre-configured in the database so that when and accident message is received, the system can resolve the identity and ownership of the vehicle involved.

\section{RESULTS}

After full implementation and testing of the system, evaluation of the prototype was done with the aim to determine if the developed system is delivering the expected results. The following areas were evaluated to provide answers to the research questions set at the feasibility study of the project, which are in line with the project objectives and requirements.

\subsection{Determining possibility of interfacing impact sensors with a GPS device}

To ascertain this, 50 impacts were initiated against the impact sensors used in the prototype. The success rates of impact signal transmission were recorded in a table in MS SQL server database. Using MS SQL server data query and analysis tools, the data was analyzed and the following table presents a summary of the statistics taken in this experiment.
Table 1. Summary of the evaluation results of interfacing Impact Sensor with GPS Device

\begin{tabular}{|c|c|c|}
\hline $\begin{array}{c}\text { Number of Accident } \\
\text { Impacts in } \\
\text { Experiment }\end{array}$ & $\begin{array}{c}\text { Sensor } \\
\text { Interface } \\
\text { Failure }\end{array}$ & $\begin{array}{c}\text { Sensor } \\
\text { Interface } \\
\text { Success }\end{array}$ \\
\hline 50 & 1 & 49 \\
\hline
\end{tabular}

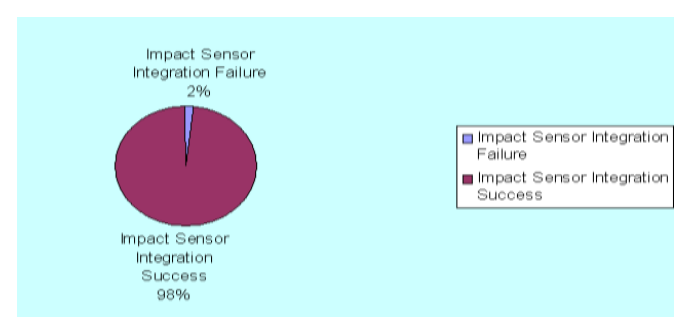

Fig 4. Pie Chart showing the success rate of interfacing the Impact sensor with GPS device

During the tests carried out in evaluation it was determined reasons why an impact sensor may fail to transmit impact signal successfully to an interfaced GPS device. These are:-

- The impact generated is too weak below the set threshold.

- When the physical interface has been interfered with causing disconnection.

- When the GPS device is not powered

- If the ECU is not powered

\subsection{Measuring success rate of GPS device} combining accident impact and spatial data prior to transmission to web based database In carrying out this evaluation, 50 impacts were initiated against the impact sensor used in the prototype. The aim was to generate impact signal for transmission to the GPS device and subsequent integration with the GPS current spatial data at the time of the accident simulation. The success rate of this integration was recorded in a table in MS SQL server database. Using MS SQL server data query and analysis tools, the data was analyzed and the following table presents a summary of the statistics taken in this experiment.

Table 2. Evaluation results of Integrating impact data and GPS spatial data

\begin{tabular}{|c|c|c|}
\hline $\begin{array}{c}\text { Number of } \\
\text { Accident } \\
\text { Impacts }\end{array}$ & $\begin{array}{c}\text { Impact \& Spatial } \\
\text { Data Integration } \\
\text { Failure }\end{array}$ & $\begin{array}{c}\text { Impact \& Spatial } \\
\text { Data Integration } \\
\text { Success }\end{array}$ \\
\hline 50 & 1 & 49 \\
\hline
\end{tabular}

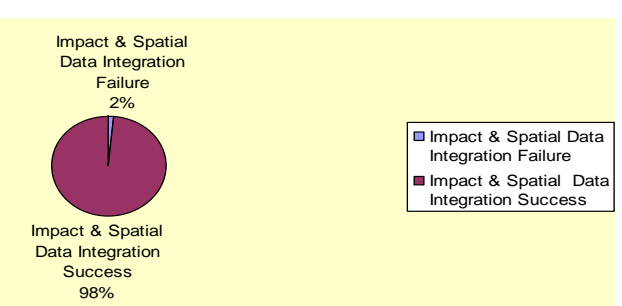

Fig 5. Pie Chart showing the success rate of Integrating Impact data and GPS spatial data

Possible reasons for experiencing incidents of failure of the GPS device's was evaluated as well as the system's ability to consolidate impact data with the GPS location data. Here, it 
was found that the following that the following are possible reasons:-

- When the GPS device has just started after power on. It takes a mean time of 1 minute and 40 seconds for the GPS device to start functioning.

- When the GPS aerial is not installed in place.

- When the GPS device is hindered from the sky by obstructing objects like buildings etc.

In all the cases above, impacts initiated are transmitted with zero padded geographical coordinates.

\subsection{Determining success rate of Web based accident database receiving accident data}

The time taken and the success rate of the accident incident update were recorded in a table in MS SQL server database. Successful update is in respect of the vehicle details, the accident location in geographical coordinates of longitudes and latitudes, date and time of the accident and the vehicle speed at the time of the accident. Using data that was generated by initiating impact on the sensors from the previous evaluations, 50 instances of impacts were analyzed. Using MS SQL server data query and analysis tools, the data was analyzed and the following table presents a summary of the statistics taken in this experiment.

The GPS Device transmitted to the database its GPS units ID that corresponds with the one that already exists on the database, enabling the system to unveil all other details of the vehicle supposedly involved in an accident impact. Most important information on display at each impact incident is the vehicle registration number. The evaluation achieved $100 \%$ success rate in this test.

Table 3. Results on the accuracy of various aspects of accident as updated on the accident database

\begin{tabular}{|l|c|c|}
\hline \multicolumn{1}{|c|}{ Details } & Correct & Wrong \\
\hline Vehicle Registration & 50 & 0 \\
\hline Location & 46 & 4 \\
\hline Date and Time & 48 & 2 \\
\hline Speed & 44 & 6 \\
\hline
\end{tabular}

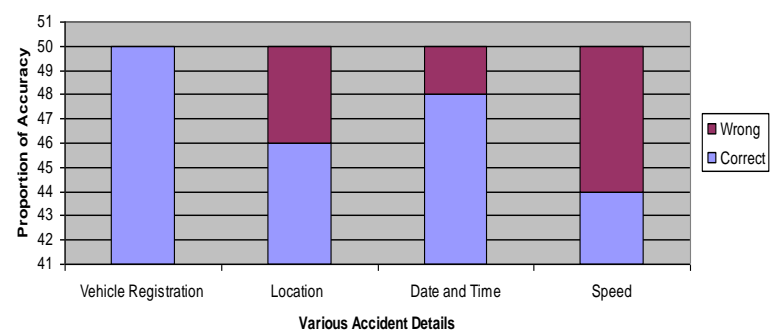

Fig 6. Accuracy of various aspects of accidents updated on the database

To determine the accuracy of the location coordinates submitted to the database on each impact, a different GPS device - a cell phone handset with GPS capabilities - was used. Coordinates of the impact site as updated on the database was compared with details on the cell phone handset. The following table is a sample of the spatial data comparison on the two devices.
Table 4. Sample of the spatial data of the two GPS devices

\begin{tabular}{|c|c|c|c|c|c|}
\hline \multicolumn{2}{|c|}{$\begin{array}{c}\text { GPS Device } \\
\text { Coordinates }\end{array}$} & \multicolumn{2}{c|}{$\begin{array}{c}\text { Cell phone GPS } \\
\text { Coordinates }\end{array}$} & \multicolumn{2}{c|}{ Variations } \\
\hline Latitude & Longitude & Latitude & Longitude & Latitude & Longitude \\
\hline 0116 & 03650 & 0116 & 03650 & & \\
$02.44 \mathrm{~S}$ & $36.89 \mathrm{E}$ & $02.44 \mathrm{~S}$ & $36.89 \mathrm{E}$ & Nil & Nil \\
\hline 0116 & 03650 & 0116 & 03650 & & \\
$02.90 \mathrm{~S}$ & $37.10 \mathrm{E}$ & $02.81 \mathrm{~S}$ & $36.91 \mathrm{E}$ & -0.11 & -0.19 \\
\hline 0116 & 03650 & 0116 & 03650 & & \\
$02.67 \mathrm{~S}$ & $36.18 \mathrm{E}$ & $02.67 \mathrm{~S}$ & $36.18 \mathrm{E}$ & Nil & Nil \\
\hline 0116 & 03650 & 0116 & 03650 & & \\
$01.70 \mathrm{~S}$ & $38.70 \mathrm{E}$ & $01.70 \mathrm{~S}$ & $38.70 \mathrm{E}$ & Nil & Nil \\
\hline 0116 & 03650 & 0116 & 03650 & & \\
$01.20 \mathrm{~S}$ & $37.67 \mathrm{E}$ & $01.20 \mathrm{~S}$ & $37.67 \mathrm{E}$ & Nil & Nil \\
\hline 0116 & 03650 & 0116 & 03650 & & \\
$03.40 \mathrm{~S}$ & $38.15 \mathrm{E}$ & $04.01 \mathrm{~S}$ & $38.30 \mathrm{E}$ & 0.61 & 0.15 \\
\hline
\end{tabular}

It was ascertained from review on GPS literature, one reason why GPS device could sometime give wrong location data. This is due errors introduced on the location data by the owners of the GPS System. However the variations are minimal and would not affect successful implementation of the system.

Table 5. Date and time comparison on the two clocks

\begin{tabular}{|c|c|c|c|l|c|}
\hline $\begin{array}{c}\text { GPS Device } \\
\text { Database Record on }\end{array}$ & \multicolumn{2}{c|}{$\begin{array}{c}\text { External Clock } \\
\text { Record on }\end{array}$} & \multicolumn{2}{c|}{ Variations } \\
\hline Date & Time & Date & Time & Date & Time \\
\hline $20 / 05 / 2012$ & $13: 15: 00$ & $20 / 05 / 2012$ & $13: 04: 45$ & Nil & $00: 10: 20$ \\
\hline $20 / 05 / 2012$ & $13: 35: 10$ & $20 / 05 / 2012$ & $13: 22: 50$ & Nil & $00: 12: 20$ \\
\hline $20 / 05 / 2012$ & $13: 56: 33$ & $20 / 05 / 2012$ & $13: 40: 15$ & Nil & $00: 13: 18$ \\
\hline $27 / 05 / 2012$ & $14: 09: 56$ & $27 / 05 / 2012$ & $14: 00: 56$ & Nil & $00: 09: 00$ \\
\hline $27 / 05 / 2012$ & $15: 20: 03$ & $27 / 05 / 2012$ & $14: 59: 43$ & Nil & $00: 20: 21$ \\
\hline $27 / 05 / 2012$ & $15: 28: 23$ & $27 / 05 / 2012$ & $15: 18: 02$ & Nil & $00: 10: 21$ \\
\hline $27 / 05 / 2012$ & $15: 38: 46$ & $27 / 05 / 2012$ & $15: 30: 30$ & Nil & $00: 08: 16$ \\
\hline
\end{tabular}

Based on the data recorded in the table shown above, time variations of less than 15 second were considered as successful cases. This is because it takes some seconds for the impact signal to reach the GPS device where transmission to the database starts, with the GPS clock sensing the time. Cases where time variation exceeded 15 seconds were considered failures. Factors that caused the GPS device to relay impact signals with delay are:-

- Weak GPS signal

- Poor GPS coverage

- Congestion on the GPS Network

The GSM Network used in this research is Safaricom, which has a wide coverage in Kenya especially along all main roads. Therefore, determining the GSM provider to use is critical in achieving desired results.

\subsection{Measuring access of web database}

The measures of efficiency considered were:-

- Successful login

- Successful Accident data Enquiry and Display

- Successful Display of accident data on a GIS

- Success in receiving new accidents alerts while logged in.

- Success in manually updating accident data on the database

Fifty logins were done and data on the above measures was taken and recorded on MS SQL server database table. The 
following is a summary of the client access efficiency data as analyzed using MS SQL server data query and analysis tools.

Table 6. Accident database client access success measure

\begin{tabular}{|l|l|l|}
\hline \multicolumn{1}{|c|}{$\begin{array}{c}\text { Access Efficiency } \\
\text { Measures }\end{array}$} & Success & Failure \\
\hline Login & 50 & 0 \\
\hline Enquiry and Display & 48 & 2 \\
\hline $\begin{array}{l}\text { Display on Digital } \\
\text { Map }\end{array}$ & 45 & 5 \\
\hline $\begin{array}{l}\text { Alert on New } \\
\text { Accident }\end{array}$ & 46 & 4 \\
\hline Manual Update & 50 & 0 \\
\hline
\end{tabular}

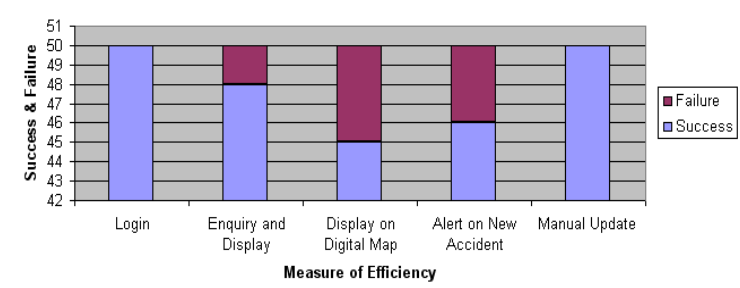

Fig 7. Measure of success for the client accident database access

\section{CONCLUSION}

The project was indeed a good opportunity to unveil what an innovation using impact sensors, GPS/GPS device, GSM network, databases, and Internet and Web technology can achieve. Literature cited alludes that there exist a gap in prompt motor vehicle accident detection and reporting mechanism especially in this country. Indeed this research comes in handy as a technology that will instantly detect and report motor vehicle accidents thereby saving lives. Results from the evaluations carried out verify that the GPS device could put together spatial data received from the satellites with the impact signal from the impact sensors. The results indicate an excellent success rate of $98 \%$ and as such asserting this configuration. This demonstrates the viability of detecting accident impacts and determining their location and time vital aspects in performing rescue activities to save the victims.

Further experiments with the prototype confirmed that the combined accident and spatial data were successfully transmitted from the GPS device to a remote web based database using GPS wireless network. Although other systems have demonstrated this capability before, it has been proved in this project that motor vehicle accident impact signals can be transmitted to a database on the web platform where it could be widely accessed. The evaluations conducted in this area were overwhelmingly encouraging with vehicle details updated correctly at the rate of $100 \%$, the accident location coordinates at $92 \%$, impact date and time at the rate of $96 \%$ and the vehicle speed at the rate of $88 \%$. Therefore these results demonstrate the viability of this solution.

The ultimate objective is to enable authorized users of the system to be able to access accident information. Evaluations carried out to measure the success level of clients accessing the accident database returned positive results. Clients could login the web page, perform enquiries and display detailed accident information on their workstations, receive new accident alerts on the screen, manually update the system with details of accidents not automatically captured in the system and even be able to display an accident on a GIS digital map, pointing to the actual location of an accident site on the map.
This in upshot means that accidents can instantly be reported to authorized personnel and agencies as and when they occur with all the necessary details to guide the authorities in rescue operations.

The various evaluations carried out in the project facilitated accumulation of up to 50 records of simulated accidents. The sample data on vehicle accidents is similar to what researcher in this area can query and carry out data mining exercises, discovering new knowledge on accidents; knowledge which in turn would be useful in mitigating motor vehicle accidents.

\subsection{Further work}

Further research can be carried out to enable:-

- Accident reporting by authorized users through mobile phones.

- Instant accident alert to be sent to specific mobile phones including the police and other emergency services.

- Data warehousing and data mining models on accident data to discover new knowledge and accident patterns that would help in reducing motor vehicle accidents.

- Determinations on how the different impact sensors can be used to transmit impact signal for the various type of accidents.

- Use GPRS in the place of GSM network as used in this project to transmit data to a web based accident database.

- Determine how well the system would function in case of multiple accidents involving many vehicles fitted with the accident detection system.

- Cryptography can be used to encrypt the transmitted accident signal from the GPS device, and decrypt it at the surveillance software, thus reducing the brute-force attacks.

\section{ACKNOWLEDGMENT}

The authors wish to thank Paltalk Systems for availing their electrical workshop for work of assembling the system hardware prototype.

\section{REFERENCES}

[1] World Health Organization -WHO. (2009). Global Status Report on Road Safety 2009.[online]. Available from http://www.who.int/violence_injury_prevention/road_stat us/2009/en/index.html. [Accessed: 20 February 2012].

[2] Osoro, M. E. et al. (2011). Factors associated with severity of road traffic injuries, Thika, Kenya. The Pan African Medical Journal. 8. p.20.

[3] Saidi H. S. (2003). Initial Injury Care in Nairobi, Kenya: a Call for trauma care regionalization. East African Medical Journal. 80(9). P.480-483.

[4] Ponboon, S. \& Tanaboriboon, Y. (2005). Development of road accident reporting computerized system in Thailand. Journal of the East Asia society for Transport studies. 6. p.3453-3466.

[5] Hannan, M.A. Hussain, A. \& Samad, S.A. (2010). System Interface for an Integrated Intelligent Safety System (ISS) for Vehicle Applications. Sensor. 10, 1141-1153

[6] Valeyev, K. Akbarnejad, H. \& Tundo, M. (n.d). Airbag Sensor. [Online]. Available from: http://www.scribd .com/doc /44311669/Airbag-Sensor . [Accessed: 24 November 2011] 
[7] GPS 2012. Encyclopadia Britannica Online. Retrieved 12 April, 2012, from HYPERLINK "http://www.britannica. com/EBchecked/topic/235395/GPS"

[8] Hari, D. (2008). Prehospital care of head injured patients. Neurol India. 56(4).p.415-419.

[9] Tanna, K.P. Kumar, P. \& Narayanan, S. (2010). Instant Theft Alert and Tracking System in Car. International Journal of Computer Applications. 1(21).p.29-34.

[10] Gupta, M. et al. (2011). Mining databases on World Wide Web. International Journal of Computer Science. 8(3,1).p.560-564.

[11] Hussain, D. M. A. (ed). (2009). Advances in Computer Science and IT. Vukovar: In-tech

[12] Misra, P. Enge P. (2006). Global Positioning System: Signals, Measurements, and Performance. Lincoln, MA. Ganga-Jamuna Press.
[13] Wiehe, S. E et al, (2008). Using GPS-enabled cell phones to track the travel patterns of adolescents. International Journal of Health Geographics. 7(22).

[14] Brian, H. \& Matthew, W. (1999). Simply Scheme: Introducing Computer Science. Manchester City. MIT Press.

[15] LandAirSea Systems, Inc. (c.2011). [Online]. How GPS Tracking Works. [Online].Available from: http://www. landairsea .com. [Accessed: 22nd December 2011]

[16] Eldon, Y. L. (1990). Software Testing In A System Development Process: A Life Cycle Perspective. Journal of System Management. 41 (8).P.23-31

[17] Howdoesvehicletrackingwork UK. (c.2011). How Does Vehicle Tracking Work. [Online]. Available from: http://www.howdoesvehicletrackingwork.co.uk. [Accessed: 22nd December 2011] 